\title{
Reaction time of patients with Parkinson's disease, with reference to asymmetry of neurological signs
}

\author{
FUSAKO YOKOCHI, RYUICHI NAKAMURA, ${ }^{*}$ HIROTARO NARABA YASHI \\ From the Department of Neurology, Juntendo University School of Medicine, Tokyo and the Institute of \\ Rehabilitation Medicine Tohoku University School of Medicine Miyagi, ${ }^{*}$ Japan
}

SUMMARY Electromyographic reaction times of the left and the right finger extensor muscles in extension movement of the wrist were examined in 42 patients with Parkinson's disease, and 20 normal subjects. Compared to the normal subjects and the patients with neurological signs confined to the right side, the patients with neurological signs on the left side or on both sides showed slowing of reaction times regardless of the side of responding hand. The patients with asymmetry of bilateral neurological signs showed slower RTs on the more affected side.

Recently several studies have been performed on reaction times in patients with Parkinson's disease to analyse the underlying perceptual-motor and cognitive disorders. ${ }^{2}$ Although studies employing more complex tasks have found slower and more variable reaction time among patients, the results for simple reaction time are still contradictory. ${ }^{3}$ Some authors reported that reaction times of patients were within the normal range or slightly longer than normal, ${ }^{4-6}$ whereas others concluded that reaction times of patients were definitely longer than those of normal subjects. ${ }^{78}$ It is likely that some of the neurological signs characteristic of Parkinsonian patients are related to the prolongation of their reaction times. For instance, reaction times of patients with akinesia were markedly prolonged ${ }^{10}$ and the reaction times of the most severely incapacitated patients were significantly long, compared to either normal subjects or patients with mild or moderate disability. ${ }^{\prime \prime}$ Diversity of these previous results can be attributed partly to the experimental conditions, such as tasks performed and patients selected for the study. According to studies of patients with cerebral lesion, definite prolongation of reaction times were

Address for reprint requests to: Fusako Yokochi, MD, Department of Neurology, Juntendo University School of Medicine, 2-1-1, Hongo, Bunkyo-ku, Tokyo 113, Japan.

Received 24 July 1984 and in revised form 16 November 1984. Accepted 23 November 1984 observed mostly in patients with right hemispheric lesions. ${ }^{12-14}$ Moreover, a lesion of the right basal ganglia is supposed to be responsible for the prolongation of reaction times, ${ }^{15}$ although the reason why damage of the right basal ganglia causes reaction time slowing has not been clarified. The projection of preparatory visual stimuli to the right hemisphere gives rise to shortening of reaction times on either side in normal subjects. This phenomenon is explained by the asymmetry of arousal or activation mechanism between hemispheres. ${ }^{16}$ If the right hemisphere, especially the right basal ganglia, plays a dominant role on arousal or activation, Parkinsonian patients affected on the left side predominantly should have marked prolongation of reaction times. However, relationship between the asymmetry of neurological signs and reaction times in Parkinsonian patients has not been analysed in detail.

In this study, EMG-reaction times of the left and the right wrist extensor muscles were examined in normal subjects and Parkinsonian patients with asymmetrical neurological signs, and the underlying mechanisms for the prolongation of reaction times were explored.

\section{Method}

The experiment was performed on 20 subjects without neurological disorders and 42 patients with Parkinson's disease (table). They were all right-handed. The age and 
Table Summary of subjects and mean reaction times (ms)

\begin{tabular}{|c|c|c|c|c|}
\hline & Control & $\begin{array}{l}\text { Group } I \\
(L<R)\end{array}$ & $\begin{array}{l}\text { Group II } \\
(L>R)\end{array}$ & $\begin{array}{l}\text { Group } I I I \\
(L=R)\end{array}$ \\
\hline $\begin{array}{l}\text { Number } \\
\text { Ages }(\mathrm{yr}) \\
\text { Sex }(\mathrm{M} / \mathrm{F}) \\
\text { Stage }(\mathrm{I}, \mathrm{II} / \mathrm{III}) \\
\text { Duration of illness (yr) }\end{array}$ & $\begin{array}{l}20 \\
58 \cdot 1(7 \cdot 4) \\
12 / 8\end{array}$ & $\begin{array}{l}13 \\
63 \cdot 1(8 \cdot 3) \\
6 / 7 \\
8 / 5 \\
5 \cdot 6(3 \cdot 6)\end{array}$ & $\begin{array}{l}14 \\
59 \cdot 4(6 \cdot 9) \\
6 / 8 \\
9 / 5 \\
5 \cdot 6(3 \cdot 7)\end{array}$ & $\begin{array}{l}15 \\
60 \cdot 5(7 \cdot 0) \\
5 / 10 \\
7 / 8 \\
7 \cdot 9(6 \cdot 1)\end{array}$ \\
\hline $\begin{array}{l}\mathrm{L} \\
\mathbf{R} \\
\text { Overall mean }\end{array}$ & $\begin{array}{l}98 \cdot 6(11 \cdot 3) \\
98 \cdot 5(8 \cdot 0) \\
98 \cdot 5(9 \cdot 4)\end{array}$ & $\begin{array}{l}110 \cdot 9(14 \cdot 5) \\
119 \cdot 6(23 \cdot 0) \\
115 \cdot 2(18 \cdot 3)\end{array}$ & $\begin{array}{l}145 \cdot 4(32.9) \\
135 \cdot 7(30 \cdot 8) \\
140.6(31 \cdot 3)\end{array}$ & $\begin{array}{l}153 \cdot 3(38 \cdot 8) \\
151 \cdot 2(33 \cdot 1) \\
152 \cdot 2(34 \cdot 9)\end{array}$ \\
\hline
\end{tabular}

L: the left finger extensors

$R$ : the right finger extensors

$($ ): standard deviation

the sex of the control subjects were matched with those of the patients. The patients were selected with stage I to III of clinical disability. ${ }^{17}$ The patients were divided into three groups based on the asymmetry of neurological signs between the left and right arms. Tremor and rigidity were rated clinically on a five point scale from 0 to 4 . When a patient's total score of both signs on one side was at least twice that of the other side, he/she was classified into the group with lateralised signs: patients with high score on the right side as group I $(L<R)$, those with high score on the left as group II $(\mathrm{L}>\mathrm{R})$ and those with almost equal score on both sides as group III $(\mathrm{L}=\mathrm{R})$. All patients were examined while they were treated with levodopa and other antiparkinsonian drugs.

The subjects sat comfortably on a chair with the trunk upright. The forearms were placed on a table in front, with the elbow joints at $60^{\circ}$ flexion, the shoulder joints at $30^{\circ}$ flexion and the forearms in midposition. They were asked to extend either the left or the right wrist as fast as possible, responding to a sound stimulus $(1,000 \mathrm{~Hz}, 50 \mathrm{~ms})$ presented at about $2 \mathrm{~s}$ after a warning signal. EMGs were taken from finger extensor muscles of the forearms with surface electrodes and displayed on a memoscope (ATAC-250, NIHONKODEN) which had been triggered by an electric signal synchronised with the sound stimulus. The EMG latencies were measured with a ms scale (reaction time). The subjects were submitted to a preliminary training session before the experimental run. The response sides were changed after every six trials. Four blocks of six trials were performed on each side. The inter-trial intervals were from 10 to $20 \mathrm{~s}$. The first trial of each block was discarded from the data and the remaining 20 trials were used for statistical analysis.

\section{Results}

The table shows the means and SDs of reaction time in each group. Reaction times of the control group and the three Parkinsonian groups were evaluated by a two-way analysis of variance, group $\times$ hand. There was a significant main effect of group $(F=$ $15 \cdot 11$, df $=3 / 58, \mathrm{p}<0 \cdot 01)$ and interaction $(F=$ $4 \cdot 66, \mathrm{df}=3 / 58, \mathrm{p}<0.05)$, but a main effect of hand was not significant $(F=0.28$, df $=1 / 58)$. The overall mean of reaction times of each group was used for comparison of reaction times between the groups. The reaction time of the control group was significantly faster than reaction times of the three Parkinsonian groups (vs GI: $t^{\prime}=2 \cdot 93$, df $=16$, p < 0.01, vs GII: $t^{\prime}=4.90, \mathrm{df}=16, \mathrm{p}<0.001$, vs GIII: $t^{\prime}=5.61, d f=16, p<0.001$, respectively; $t$ : Student's $t$ test, $t^{\prime}$ : Welch's method). Among the Parkinsonian groups, group I showed faster reaction time than group II and III (vs GII: $\mathbf{t}^{\prime}=2 \cdot 53$, df $=$ $23, p<0.05$, vs GIII: $\left.t^{\prime}=3.45, d f=22, p<0.01\right)$. There was no significant difference of reaction times between group II and III $(\mathrm{t}=1 \cdot \mathbf{0} 1, \mathrm{df}=28)$.

Comparison of reaction times between the left and the right side showed that there was no significant difference in the control group $(t=0.06$, $\mathrm{df}=19)$ and group III $(\mathrm{t}=0.45, \mathrm{df}=14)$. Reaction time of the right hand was slower than that of the left in group $I(t=2 \cdot 54, d f=12, p<0 \cdot 05)$. Reaction time of the left hand was slower than that of the right in group II $(\mathrm{t}=2.84, \mathrm{df}=13, \mathrm{p}<0.02)$.

\section{Discussion}

The main finding in this study was that patients with Parkinson's disease belonging to stages I, II or III $^{17}$ had definitely prolonged reaction times, compared to age-matched normal subjects. Asymmetry of neurological signs was more important in determining the prolongation of reaction time than the severity of disability. Patients with neurological signs predominantly on the left side showed a clear slowing of reaction times regardless of the responding hand, compared to normal subjects and to patients with minor neurological signs on the left side. Another finding was that when the comparison of reaction times was made between the left and the right hands of the patients, reaction times were slower on the side neurologically more affected than on the side less affected.

Reaction time prolongation in Parkinsonian patients was partly attributed to lengthening of the 
interval between the onset of EMG activities of the prime mover muscle and the ensuing movement. ${ }^{18}$ However, this factor was eliminated in the present study, since EMG-reaction times were utilised instead of mechanical reaction times. The prolongation observed in Parkinsonian patients could be caused by the delayed information processing in the central nervous system.

These results could be interpreted as follows: the bilateral or generalised prolongation of reaction times is caused at least by dysfunction of the right basal ganglia, and the unilateral or localised prolongation of reaction times is caused by dysfunction of the contralateral basal ganglia to the responding side. Overall slowing of reaction times, thus, is the sum of these two factors.

Recently DeLong et al, ${ }^{19} 20$ based on anatomical features of the striatum, have suggested that there are two distinct roles for the striatum. One is performed by the putamen and concerns strictly motor function, the other by the caudate concerns complex behavioral function. Since the substantia nigra sends fibres to these two nuclei to modulate their function, the abnormality of both the behaviour and the motor function should occur simultaneously in Parkinsonian patients. In experiments such as the present one, the bilateral prolongation of reaction times would be related to the complex behaviour function of the caudate and the unilateral one to the motor function of the putamen.

As for the asymmetry of the basal ganglia dysfunction between the left and the right for the prolongation of bilateral reaction times, the most plausible explanation is the asymmetry of an arousal or activation mechanism. ${ }^{16}$ The bilateral prolongation of reaction times would be related to the decreased arousal level of Parkinsonian patients due to the lesion of the right basal ganglia.

Dysfunction of each basal ganglia seems to produce reaction time prolongation of the contralateral side. Gross et al, ${ }^{21}$ examining the latency from an auditory signal to changes in activity of a cortical neuron in area 4 and to beginning of forearm movements on a reaction time task before and after a nigral lesion in monkeys, reported that the latency between the signal and the changes in neuronal activity was unchanged, but the time between the onset of the neuronal changes and the start of forearm movements increased significantly. The frequency of the neuronal discharge was reduced in animals with nigral lesions so they concluded that the nigral lesion induced a perturbation in build up of the motor cortical area output. The similarity of data in reaction time experiments in patients with Parkinson's disease and monkeys with the nigral lesion suggests that the decrease of output from cor- tical neurons in the motor area is responsible for the prolonged reaction times contralateral to the affected basal ganglia in the patients.

\section{References}

' Flowers K. Lack of prediction in the motor behaviour of parkinsonism. Brain 1978;101:35-52.

${ }^{2}$ Evarts EV, Terävärinen H, Calne DB. Reaction time in Parkinson's disease. Brain 1981;104:167-86.

${ }^{3}$ Nettelbeck T. Factors affecting reaction time: Mental retardation, brain damage and other psychopathologies. In: Welford AT, ed. Reaction Times. London: Academic Press 1980:355-401.

${ }^{4}$ King HE. Defective psychomotor movement in Parkinson's disease: Exploratory observations. Percept Mot Skills 1959;9:326.

${ }^{5}$ Wiesendanger M, Schneider P, Villoz JP. Electromyographic analysis of a rapid volitional movement. Am J Physical Med 1969;48:17-24.

- Nakamura R, Taniguchi R. Dependence of reaction times on movement patterns in patients with Parkinson's disease and those with cerebellar degeneration. Tohoku J Exp Med 1980;132:153-8.

${ }^{7}$ Draper IT. Johns RJ. The disordered movement in parkinsonism and the effect of drug treatment. Bull Johns Hopkins Hosp 1964;115:465-480.

${ }^{8}$ Heilman KM, Bowers D, Watson RT, Greer M. Reaction times in Parkinson's disease. Arch Neurol 1979;44:139-40.

${ }^{9}$ Brumlik J, Boshes B. The mechanism of bradykinesia in parkinsonism. Neurology (Minneap) 1966;16:337-44.

10 Joubert M, Barbeau A. Akinesia in Parkinson's disease. In: Barbeau A, Brunette JR, eds. Progress in Neurogenetics. Amsterdam: Excerpta Medica Foundation 1969:366-76.

"Talland GA. Manual skill in Parkinson's disease. Geriatrics 1963;18:613-20.

12 Benton AL, Joynt R. Reaction times in unilateral cerebral disease. Confun Neurol 1959;19:247-56.

${ }^{13}$ Dee HL, Van Allen MW. Simple and choice reaction time and motor strength in unilateral cerebral disease. Acta Psychiat Scand 1971;47:315-23.

${ }^{14}$ Nakamura R, Taniguchi R. Reaction time in patients with cerebral hemiparesis. Neuropsychologia 1977; 15:845-8.

is Howes D, Boller F. Simple reaction time: Evidence for focal impairment from lesions of the right hemisphere. Brain 1975;98:317-32.

${ }^{16}$ Heilman KM, Van den Abell T. Right hemispheric dominance for mediating cerebral activation. Neuropsychologia 1979;17:315-21.

${ }^{17}$ Hoehn MM, Yahr MD. Parkinsonism; onset, progression and mortality. Neurology (Minneap) 1967; 17:427-42.

${ }^{18}$ Hallett M, Shahani BT, Young RR. Analysis of stereotyped voluntary movements at the elbow in patients with Parkinson's disease. J Neurol Neurosurg Psychiatry 1977;40:1129-35.

19 DeLong MR, Georgopoulos AP. Motor functions of the basal ganglia. In: Brookhart JM, Mountcastle VB, 
eds. Handbook of Physiology, Sect. I: The Nervous System, Vol. II. Motor Control. Bethesda: American Physiological Society 1981:1017-61.

${ }^{20}$ DeLong MR, Georgopoulos AP, Crutcher MD. Cortico-basal ganglia relations and coding of motor performance. In: Massion J, Paillard J, Schultz W, Wiesendanger M, eds. Neural Coding of Motor Performance (Exp Brain Res, Suppl 7), Berlin:
Springer-Verlag 1983:30-40.

${ }^{21}$ Gross Ch, Feger J, Seal J, Haramburu Ph, Bioulac B. Neuronal activity in area 4 and movement parameters recorded in trained monkeys after unilateral of the substantia nigra. In: Massion J. Paillard J, Schultz W, Wiesendanger M, eds. Neural Coding of Motor Performance (Exp Brain Res, Suppl 7). Berlin: Springer-Verlag 1983:181-93. 